\title{
Pengaruh Waktu Detensi pada Anaerobik Digester Sistem dua Tahap dengan Substrat Tanah Gambut terhadap Produktivitas Biogas
}

\author{
Alca Pratama Putra ${ }^{1}$, Etih Hartati ${ }^{1}$, Salafudin ${ }^{2}$ \\ 1) Jurusan Teknik Lingkungan, Institut Teknologi Nasional (Itenas), Bandung \\ 2) Jurusan Teknik Kimia, Institut Teknologi Nasional (Itenas), Bandung \\ Email: alcapratama3030@gmail.com
}

\begin{abstract}
Abstrak
Indonesia memiliki $50 \%$ dari luas lahan gambut yang ada di dunia. Tanah gambut merupakan tanah yang berasal dari proses dekomposisi materi organik dari sisa tumbuhan. Materi organik yang terkandung dalam tanah gambut dapat dimanfaatkan sebagai substrat dalam pembentukan biogas. Keberadaan tanah gambut di Indonesia berkisar 21 juta hektar sehingga berpotensi besar dalam membuat biogas dari tanah gambut. Biogas dapat dimanfaatkan sebagai bahan bakar alternatif yang ramah lingkungan. Tujuan dari penelitian ini adalah mengetahui potensi tanah gambut sebagai substrat dalam pembentukan biogas. Metode yang digunakan dalam penelitian ini adalah two stage digestion system dimana tahap pembentukan asam dilakukan di reaktor hidrolisis secara batch sedangkan tahap pembentukan gas $\mathrm{CH}_{4}$ dilakukan di reaktor metanogenesis secara kontinu. Variasi yang digunakan pada penelitian ini adalah waktu detensi 1 hari dan 4 hari. Hasil optimum yang didapatkan pada variasi waktu detensi 4 hari dengan laju produksi biogas sebesar 395 $\mathrm{ml} /$ hari dan konsentrasi gas $\mathrm{CH}_{4}$ sebesar $61 \%$.
\end{abstract}

Kata Kunci : Tanah gambut, Biogas, Waktu detensi, two stage digestion system

\begin{abstract}
Indonesia has $50 \%$ of the world's peatland. Peat soil is a soil derived from the decomposition process of organic matter from the rest of the plant. Organic matter contained in peat soils can be utilized as a substrate in the formation of biogas. The existence of peat soil in Indonesia ranges from 21 million hectares so it has great potential in making biogas from peat soil. Biogas can be utilized as an environmentally friendly alternative fuel. The purpose of this research is to know the potential of peat soil as substrate in biogas formation. The method used in this research is two stage digestion system where the acid formation stage is done in the batch hydrolysis reactor while the $\mathrm{CH}_{4}$ gas formation stage is done in methanogenesis reactor continuously. The variation used in this research is the detention time of 1 day and 4 days. The optimum result on 4 day detention variation with biogas production rate of $395 \mathrm{ml} /$ day and $\mathrm{CH}_{4}$ gas concentration of $61 \%$.
\end{abstract}

Keywords: peat soil, biogas, detention time, two stage digestion system 


\section{Pendahuluan}

Indonesia memiliki lahan gambut terluas di antara negara tropis, yaitu sekitar 21 juta ha atau $10.8 \%$ dari luas daratan Indonesia. Keberadaan gambut pada suatu bentang lahan saat ini adalah penting peranannya pada konservasi karbon, mengingat sebagain besar hutan rawa gambut telah kehilangan vegetasi dan terdegradasi. Oleh karena itu, gambut merupakan cadangan karbon yang masih tersisa pada suatu bentang lahan. Pada kondisi alami, lahan gambut berperan sangat penting dalam siklus karbon (C) global (Bartlett and Harriss, 1993). Lahan gambut mampu menyimpan paling sedikit 550 gigaton karbon dua kali lipat jumlah karbon yang tersimpan di hutan seluruh dunia. Karbon yang terkandung dalam lahan gambut dapat keluar ke udara, sehingga menimbulkan emisi gas yang berbahaya bagi dunia (Wetlands international, 2009).

Untuk itu dilakukan penelitian mengenai biogas dari tanah gambut ketika emisi yang dikeluarkan dari tanah gambut dikonversikan menjadi biogas. Indonesia sangat berpotensi untuk mengkonversikan tanah gambut menjadi biogas sebagai sumber bahan bakar alternatif. Gas metana yang keluar dari gambut dapat dimanfaatkan sebagai biogas. Biogas adalah gas yang dihasilkan dari proses penguraian bahan-bahan organik oleh mikroorganisme dalam kondisi tanpa oksigen (anaerobik). Energi yang terkandung didalam biogas tergantung dari kandungan metan dalam biogas. (Wahyudi dkk, 2012).

Penelitian ini dilakukan secara anaerobik dengan two stage anaerobic digestion system menggunakan 2 buah reaktor secara terpisah yaitu reaktor hidrolis is berkapasitas 30 $L$ dengan bahan dasar plastik dan reaktor metanogenesis berkapasitas $1,46 \mathrm{~L}$ dengan bahan dasar akrilik.

\section{METODOLOGI}

\section{$2.1 \quad$ Studi Literatur}

Pada penelitian ini studi literatur sangat berguna untuk mendukung serta meningkatkan pemahaman mengenai kajian yang terdapat pada penelitian ini. Studi literatur penelitian ini diambil dari buku mengenai biogas, jurnal ilmiah, laporan tugas akhir, dan penelusuran internet yang berkaitan tentang kajian pada penelitian ini.

\subsection{Tahap Pendahuluan}

\subsubsection{Perancangan dan Persiapan serta Media pada Reaktor}

Pada persiapan reaktor dan media yang digunakan dimulai dengan merancang reaktor, survei tempat serta alat/material reaktor, kemudian perancangan reaktor.

\section{a. Design Reaktor}

Dalam hal ini mendesign reaktor dimulai dengan pembuatan sketsa gambar reaktor, pembuatan skema reaktor keseluruhan. Dalam hal ini perancangan reaktor hidrolis is (reaktor pembentukan asam) dan reaktor metanogenesis (reaktor pembentukan gas metan).

\section{b. Pembelian Material Pelengkap Reaktor}

Pada material pelengkap reaktor yang dibutuhkan adalah pipa acrylic untuk badan reaktor dan flank (reaktor metanogenesis), plug inlet dan outlet, selang PU, keran, pompa, adaptor, sambungan T, pipa PVC untuk akumulator, media reaktor metanogenesis yaitu bambu (sumpit), plastik mika lembaran dan pentil roda tubles untuk pembuatan gas holder (penampung gas). 


\section{c. Perancangan Reaktor}

Pada tahap perancangan, reaktor yang digunakan pada penelitian ini ada dua jenis, yaitu reaktor hidrolisis dan reaktor metanogenesis. Reaktor hidrolisis terbuat dari plastik dan reaktor metanogenesis berbahan dasar akrilik.

$>\quad$ Reaktor Hidrolisis dan Reaktor Metanogenesis

Reaktor hidrolisis digunakan berbentuk tabung berbahan plastik. Reaktor ini dipilih karena terjangkau, mudah didapat serta kapasitasnya yang kecil yaitu $30 \mathrm{~L}$ dan volume operasionalnya adalah $12 \mathrm{~L}$. Reaktor hidrolisis dioperasikan secara batch, yang mana sampah organik dan air pembilas (bahan baku substrat) dimasukkan hanya sekali pada awal proses dan tanpa adanya penambahan bahan lain selama proses. Reaktor ini dilengkapi dengan tutup di bagian atas dan kran di bagian bawah. Tutup reaktor berfungsi untuk melindungi substrat di dalam reaktor dan agar dalam kondisi anaerob, sedangkan keran berfungsi untuk mengalirkan substrat ke dalam penampung yang selanjutnya substrat akan dipompakan ke dalam reaktor metanogenesis.

Reaktor metanogenesis yang digunakan berbentuk tabung berbahan dasar akrilik sehingga dapat dilihat perubahan yang terjadi pada media yang ada dalam reaktor. Reaktor metanogenesis yang digunakan dalam penelitian terdapat 4 unit terbuat dari akrilik dengan tebal $0,5 \mathrm{~cm}$ dan dilengkapi saluran inlet, outlet, saluran penampung gas, dan perforated plat yang berfungsi untuk meratakan distribusi aliran substrat di dalam reaktor. Tinggi total reaktor (kepala reaktor dan badan reaktor) 103,4 cm, tinggi badan reaktor $82 \mathrm{~cm}$, diameter dalam 4,5 cm, dan diameter luar $5 \mathrm{~cm}$. Sedangkan akumulator berbahan dasar PVC karena mudah didapat dan terjangkau. Akumulator ini memiliki diameter 3" (inchi), tinggi total 20,5 cm, volume total $935 \mathrm{~cm}^{3}$, dan volume operasional $750 \mathrm{~cm}^{3}(750 \mathrm{ml})$. Akumulator ini dilengkapi dengan saluran gas pada bagian tutupnya, saluran inlet substrat pada bagian samping atas, dan saluran outlet substrat pada bagian samping bawah.

Berikut merupakan material pelengkap reaktor metanogenesis yaitu :

$>$ Media pada Reaktor

Media yang digunakan pada penelitian ini adalah media bambu (sumpit). Media ini memiliki Panjang $1 \mathrm{~cm}$ dan Diameter $0,5 \mathrm{~cm}$. Media ini dipilih karena mudah didapat serta media ini merupakan media alami yang banyak terdapat di indonesia. Sebelum digunakan media ini direndam terlebih dahulu dengan air selama 1 bulan untuk melarutkan zat-zat organik yang ada pada sumpit tersebut (Hanupurti, 2009).

$>$ Pompa dan Adaptor

Pompa yang digunakan berjenis pompa DC dengan nama Micro Water Gear Pump DC RS-360SH Spray Motor. Pompa ini memiliki diameter saluran inlet $4 \mathrm{~mm}$ dan outlet 3 $\mathrm{mm}$, terbuat dari material metal dan plastik, dimensi $4,2 \mathrm{~cm} \times 4,5 \mathrm{~cm} \times 6,5 \mathrm{~cm}$. Setiap pompa membutuhkan adaptor $12 \mathrm{~V} 1 \mathrm{~A}$. Pada penelitian ini setiap reaktor metanogenesis menggunakan satu buah pompa dan satu buah adaptor.

$>$ Gas holder

Gas holder ini ada pada di reaktor metanogenesis dan akumulator, hal ini berfungsi untuk menampung biogas yang terbentuk. Gas holder ini berbahan dasar dari plastik mika yang telah dipotong dengan ukuran $30 \times 30 \mathrm{~cm}$ dan direkatkan tiap sisinya dengan menggunakan alat perekat plastic (sealer) agar tidak bocor. Gas holder ini dilengkapi dengan pentil yang tersambung dengan selang serta diberi keran.

$>$ Dimmer dan keran

Dimmer ini berfungsi untuk mengatur debit pada pompa, sehingga pompa yang digunakan dapat diatur debit outlet-nya ( $4 \mathrm{~mL} /$ detik). Keran yang digunakan adalah keran merek TORA berukuran $1 / 4$ inch. Keran di bawah reaktor berfungsi ketika pompa 
bermasalah keran ini dapat ditutup dan substrat masih ada di dalam reaktor. Selama proses berlangsung substrat disirkulasikan dari mulai masuk ke reaktor kemudian mengalir ke akumulator dan kembali lagi ke reaktor selama 24 jam.

Perancangan reaktor meliputi perakitan reaktor metanogenesis dengan komponen/material pelengkapnya. Berikut merupakan skema reaktor yang digunakan dalam penelitian ini dapat dilihat pada Gambar 3.1.

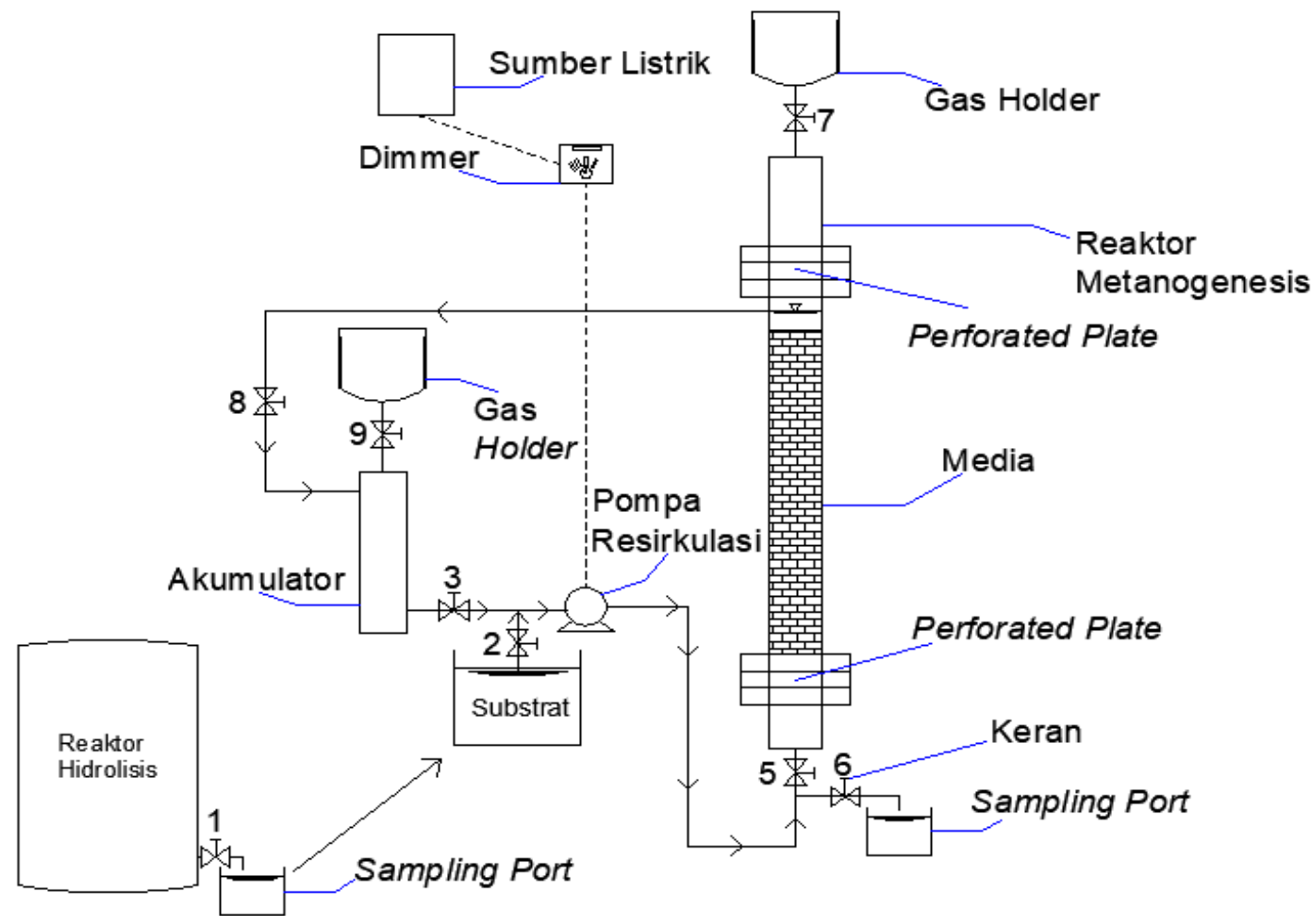

Gambar 3.1 Skema Reaktor

Substrat dari reaktor hidrolisis masuk ke reaktor metanogenesis dengan menggunakan pompa. Pada saat substrat dari reaktor hidrolisis dipompakan, keran nomor 2 dibuka dan keran nomor 3 ditutup sehingga substrat masuk ke reaktor metanogenesis dan tertampung di akumulator. Setelah semua substrat masuk ke dalam akumulator, keran 2 ditutup dan keran 3 dibuka. Selama running (24 jam), substrat disirkulasikan dan keran 2 ditutup agar substrat tidak keluar melalui saluran outlet. Pengambilan sampel substrat yang ada di dalam reaktor metanogenesis dilakukan pada sampling port dengan cara menutup keran 3 dan membuka keran 6. Setelah selesai posisi keran dikembalikan seperti semula (keran 3 dibuka dan keran 6 ditutup).

\subsubsection{Sumber Tanah Gambut}

Tanah gambut diperoleh di Kelurahan Sungai Pakning, Kecamatan Bukit Riau, Kabupaten Bengkalis, Kota Riau yang dikirimkan ke Itenas sekitar 100 kg agar mencukupi untuk kebutuhan penelitian ini.

\subsubsection{Pengeringan Tanah Gambut}


Tanah gambut yang digunakan sebelumnya dikeringkan terlebih dahulu karena tanah gambut dalam keadaan basah. Pengeringan dilakukan pada suhu $105{ }^{\circ} \mathrm{C}$. Proses penghilangan kadar air dilakukan dengan suhu $105{ }^{\circ} \mathrm{C}$ (SNI 03-1965-1990). Tanah gambut yang mengandung air mengandung mikroorganisme didalamnya, sehingga tanah gambut dikeringkan sebagai alternatif pengawetan.

\subsubsection{Pengambilan Kotoran Sapi dan S/udge Limbah Domestik}

Penelitian ini menggunakan cairan manure (campuran antara kotoran sapi, air keran, dan sludge limbah domestik) sebagai sumber mikroorganisme. Kotoran sapi yang digunakan berasal dari peternakan sapi yang berada di daerah Pasir Impun, Bandung, air keran yang digunakan berasal dari Ruang Analis Laboratorium Teknik Lingkungan Itenas Bandung, sedangkan sludge limbah domestik berasal dari selokan yang ada di Kompleks Cikutra Baru Bandung. Pemilihan lokasi ini karena letaknya yang dekat dengan lokasi penelitian.

\subsubsection{Pembuatan Cairan Manure}

Pembuatan cairan manure ini dilakukan di dalam jerigen plastik dengan kapasitas 25 L. Rasio perbandingan antara kotoran sapi : air : lumpur air limbah domestik yaitu 1:2:1. Penentuan rasio antara kotoran sapi dengan air ini mengacu pada penelitian (Anggraini, dkk., 2015), sedangkan penambahan sludge air limbah domestik untuk memperkaya jenis mikroorganisme.

\subsubsection{Pengkondisian Substrat Tanah Gambut pada Reaktor Hidrolisis}

Dalam penelitian ini tanah gambut ditimbang dan dimasukkan ke dalam reaktor hidrolisis, ditambahkan s/udge manure dan air, dengan perbandingan 1:1:10. Tanah gambut dan air yang masuk ke dalam reaktor hidrolisis adalah 1,5 kg tanah gambut, 1,5 kg s/udge manure dan digenangi dengan air sampai $10 \mathrm{~cm}$ dalam hal ini ketika ditambahkan air sampai $10 \mathrm{~cm}$ air yang digunakan sebanyak $10 \mathrm{~kg}$ dengan asumsi $1 \mathrm{~L}$ air $=1 \mathrm{~kg}$ air . Campuran feses sapi, air dan cairan rumen dibuat dengan perbandingan 1:1:10 akan menghasilkan gas metan yang tinggi (Saputro dan Putri, 2011).

Penambahan air bertujuan untuk melarutkan materi organik di dalam tanah gambut. Penambahan air dapat menyebabkan mikroorganisme mudah untuk beraktivitas sehingga proses pembentukkan gas metan dalam proses anaerob berlangsung lancar (Khairani, dkk., 2015). Tujuan dari digenangi sampai $10 \mathrm{~cm}$ agar tanah gambut dan sludge manure terhidrolisis secara anaerob. Pada pengkondisian substrat ini dilakukan pengukuran parameter $\mathrm{pH}$, suhu, TAV dan COD.

\subsubsection{Seeding dan Aklimatisasi pada Reaktor Metanogenesis}

Seeding dilakukan untuk mengembangkan mikroorganisme yang digunakan untuk penelitian (Andary dkk, 2010). Pada penelitian ini tahap seeding dilakukan dengan menumbuhkan mikroorganisme pada media. Tahap awal dari seeding adalah dengan menempelkan mikroorganisme pada media bambu (sumpit). Proses tersebut dilakukan dengan cara merendam media di dalam cairan manure selama 20 hari, seeding dilakukan di dalam reaktor metanogenesis. Perendaman selama 20 hari dilakukan dengan pertimbangan bahwa dengan waktu 20 hari mikroorganisme telah menempel pada media. Seeding dilakukan dengan penambahan substrat setiap hari dengan peningkatan volume substrat sebesar $146 \mathrm{ml}$. Angka tersebut didapat 10\% dari volume operasional reaktor metanogenesis dan akumulator. Penambahan substrat dilakukan untuk memberikan nutrisi, sedangkan penambahan substrat setiap hari dengan peningkatan volume substrat sebesar $146 \mathrm{ml}$ 
bertujuan agar mikroorganisme tidak kaget dan dapat beradaptasi dengan baik terhadap substrat. Selama seeding dilakukan pengukuran parameter $\mathrm{pH}$, suhu, berat biofilm dan warna media untuk memantau agar substrat yang masuk ke dalam reaktor memenuhi persyaratan untuk dilakukan proses anaerob, yaitu rentang $\mathrm{pH}$ substrat antara 6,6 sampai 7,6 , temperatur $25-35^{\circ} \mathrm{C}$, terjadi perubahan warna dan penambahan berat pada media (Tchobanoglous, 2004).

Tahap selanjutnya adalah aklimatisasi. Aklimatisasi merupakan tahap mengkondisikan mikroorganisme agar dapat hidup dan melakukan penyesuaian diri terhadap lingkungan baru (Andary dkk, 2010). Pada tahap ini dilakukan pengukuran parameter chemical oxygen demand (COD) harian untuk mengetahui kesiapan substrat yang dilakukan pada proses selanjutnya. Steady state tercapai apabila fluktuasi penurunan nilai COD tidak melebihi $10 \%$, yang artinya mikroorganisme siap untuk dilakukan proses selanjutnya. Selain parameter $\mathrm{COD}$, dilakukan pula pengukuran parameter $\mathrm{pH}$ dan suhu.

\subsection{Running Variasi Waktu detensi dan Sirkulasi}

Pada penelitian ini variasi yang dilakukan adalah variasi waktu detensi 1 hari, 4 hari, 7 hari dan 10 hari dan sirkulasi. Terdapat 4 unit reaktor metanogenesis dengan masingmasing memiliki waktu detensi yang berbeda. Terdapat 4 unit reaktor metanogenesis yang digunakan masing-masing memiliki waktu detensi yang berbeda. Reaktor 1, Reaktor 2, Reaktor 3 dan Reaktor 4 masing-masing memiliki waktu detensi 1 hari, 4 hari, 7 hari dan 10 hari. Pada variasi waktu detensi ini dilakukan perhitungan sebagai berikut :

$$
\text { Volume Loading }=\frac{\text { Volume Operasional Reaktor }+ \text { Volume Operasional Akumulator }}{\text { Waktu detensi yang ditentukan }}
$$

Proses penambahan volume loading dan unloading substrat dari perhitungan setiap hari. Setelah dilakukan perhitungan untuk waktu detensi 1 hari, 4 hari, 7 hari dan 10 hari volume loading dan unloading substrat masing-masing sebanyak 1,46 L/hari, 0,37 L/hari, 0,21 L/hari, dan 0,15 L/hari. Pada td 1 hari, 4 hari dan 7 hari dilakukan penambahan volume loading dan unloading substrat secara bertahap yaitu sebagai berikut :

$>$ Td 1 hari : 0,15 L/hari $\rightarrow 0,21 \mathrm{~L} /$ hari $\rightarrow 0,37 \mathrm{~L} /$ hari $\rightarrow 1,46$ L/hari.

$>$ Td 4 hari : 0,15 L/hari $\rightarrow 0,21 \mathrm{~L} /$ hari $\rightarrow 0,37$ L/hari.

$>$ Td 7 hari : 0,15 L/hari $\rightarrow 0,21 \mathrm{~L} /$ hari.

$>$ Td 10 hari : 0,15 L/hari.

Hal ini bertujuan agar bakteri yang telah melalui tahap seeding dan aklimatisasi tidak shock loading sehingga dilakukan secara bertahap. Jika tidak dilakukan secara bertahap akan menyebabkan aktivitas dan kinerja dari bakteri akan terhambat dan produktivitas dalam mendegradasi substrat tanah gambut akan menurun.

Pada running debit sirkulasi dilakukan 2 variasi yaitu 15 L/jam dan 13 L/jam. Variasi debit sirkulasi dan waktu detensi dilakukan secara bersamaan. Td 1 hari, 4 hari, 7 hari dan 10 hari masing-masing dilakukan debit sirkulasi 15 L/jam dan 13 L/jam. Sirkulasi ini bertujuan agar substrat dalam keadaan homogen. Semakin cepat subsrtat disirkulasikan maka aktivitas bakteri akan lebih meningkat karena kontak antara bakteri dengan substrat akan semakin banyak. 


\section{Hasil dan Pembahasan}

\section{1 karakteristik Tanah Gambut}

Pada karakteristik tanah gambut pengukuran dilakukan untuk mengetahui kondisi awal dari tanah gambut itu sendiri, parameter-parameter yang diukur adalah $\mathrm{pH}$, Suhu, Densitas, Kadar air, Volatil Solid, C-Organik dan NTK. Berikut merupakan karakteristik dari tanah gambut pada Tabel 3.1.

Tabel 3.1 Karakteristik Tanah Gambut

\begin{tabular}{cccc}
\hline No & Parameter & satuan & $\begin{array}{c}\text { Hasil } \\
\text { Pengukuran }\end{array}$ \\
\hline $\mathbf{1}$ & $\mathrm{pH}$ & - & 3,87 \\
\hline $\mathbf{2}$ & Suhu & ${ }^{0} \mathrm{C}$ & 26,5 \\
\hline $\mathbf{3}$ & Bulk Density & $\mathrm{g} / \mathrm{cm}^{3}$ & 0,18 \\
\hline $\mathbf{4}$ & Kadar air & $\%$ & 66 \\
\hline $\mathbf{5}$ & Volatil Solid & $\%$ & 97,1 \\
\hline $\mathbf{7}$ & C-organik & $\%$ & 76,14 \\
\hline $\mathbf{8}$ & NTK & $\%$ & 3,02 \\
\hline
\end{tabular}

Sumber : Hasil Pengukuran, 2017

Pada Tabel 3.1 hasil pH yang didapat adalah 3,87 mengindikasikan bahwa tanah gambut ini diambil pada kedalaman $100 \mathrm{~cm}$. Menurut sani (2011), tanah gambut pada kedalaman $100 \mathrm{~cm}$ memiliki pH sekitar $(3,1-3,9)$. Angka Bulk Density sebesar $0,18 \mathrm{~g} / \mathrm{cm}^{3}$ menunjukan bahwa kepadatan tanah gambut, semakin tinggi densitasnya maka semakin rendah dalam meneruskan air, artinya bahwa kemampuan tanah gambut dalam menyerap air sangat besar, dan densitas $>0,1 \mathrm{~g} / \mathrm{cm}^{3}$ ketebalan dari tanah gambut itu sendiri adalah $40 \mathrm{~cm}$ (Sani, 2011).

Kadar air awal pada tanah gambut ini adalah $66 \%$. Tanah gambut yang digunakan dikeringkan kembali sebagai bentuk pengawetan. Pengawetan dilakukan dilakukan agar mikroorganisme dalam tanah gambut tidak terdegradasi dan menghindari zat toksik yang ada didalamnya (Sani, 2011). Hasil volatil solid sebesar 97,1 \% ini menujukkan bahwa secara kasar kandungan organik pada tanah gambut tersebut, sementara 2,9\% adalah kandungan anorganik atau mineral. Kadar volatil yang tinggi menunjukkan bahwa sampah organik kaya akan materi yang mudah didekomposisi oleh mikroorganisme.

Rasio $\mathrm{C} / \mathrm{N}$ pada tanah gambut ini adalah sebesar $25,21 \mathrm{C} / \mathrm{N}$, rasio menunjukkan perbandingan jumlah dari karbon dan nitrogen. Proses anaerobik akan optimum bila diberikan bahan makanan yang mengandung karbon dan nitrogen yang bersamaan. (Fry, 1974). Rasio C/N yang baik untuk proses anaerob adalah 25-35 menurut, maka tanah gambut yang digunakan cocok untuk pengolahan secara anaerob.

\subsection{Tahap Seeding dan Aklimatisasi}

\subsubsection{Tahap Seeding Reaktor Hidrolisis}

Pada tahap seeding untuk lindi tanah gambut dilakukan pada reaktor hidrolisis yang bertujuan untuk menumbuhkan bakteri dan terjadi proses hidrolisis, asidogenesis dan asetogenesis. Pada tahap ini parameter yang diuji adalah pH, suhu, TAV dan COD. Berikut hasil pengukuran selama hidrolisis pada Tabel 3.3. 
Tabel 3.3 Hasil Pengukuran Tahap Hidrolisis

\begin{tabular}{ccccc}
\hline $\begin{array}{c}\text { Hari } \\
\text { ke- }\end{array}$ & $\mathbf{p H}$ & $\begin{array}{c}\text { Suhu } \\
\left({ }^{\circ} \mathbf{C}\right)\end{array}$ & $\begin{array}{c}\text { TAV } \\
(\mathbf{m g} / \mathbf{L})\end{array}$ & $\begin{array}{c}\text { COD } \\
(\mathbf{m g} / \mathbf{L})\end{array}$ \\
\hline $\mathbf{2}$ & 6.05 & 26.6 & 264.71 & 5.440 \\
\hline $\mathbf{4}$ & 6.21 & 26.2 & 211.76 & 4.880 \\
\hline $\mathbf{6}$ & 6.22 & 26.2 & 211.76 & 4.200 \\
\hline $\mathbf{8}$ & 6.51 & 26.3 & 105.88 & 3.120 \\
\hline $\mathbf{1 0}$ & 6.34 & 26.9 & 169.41 & 2.920 \\
\hline $\mathbf{1 2}$ & 5.82 & 25.5 & 141.18 & 2.320 \\
\hline $\mathbf{1 4}$ & 6.1 & 26.2 & 282.35 & 1.840 \\
\hline $\mathbf{1 6}$ & 5.9 & 27.4 & 352.94 & 1.032 \\
\hline $\mathbf{1 8}$ & 5.70 & 26.6 & 211.76 & 1.160 \\
\hline $\mathbf{2 0}$ & 5.82 & 26.35 & 282.35 & 3.640 \\
\hline $\mathbf{2 2} *$ & 5.84 & 27.05 & 141.18 & 1.600 \\
\hline $\mathbf{2 4}$ & 4.90 & 25.65 & 667.06 & 17.360 \\
\hline $\mathbf{2 6}$ & 4.85 & 25.2 & 1058.82 & 16.320 \\
\hline $\mathbf{2 8}$ & 4.78 & 26.45 & 1411.76 & 14.720 \\
\hline $\mathbf{3 0}$ & 4.67 & 26.1 & 1648.24 & 13.880 \\
\hline $\mathbf{3 2}$ & 4.57 & 26.5 & 1800.00 & 12.280 \\
\hline Sumber : Hasil Pengukuran, 2017 & &
\end{tabular}

Keterangan :

* = hidrolisis ditambah EM4 $250 \mathrm{ml}$ dan gula merah 250 gram

Pada tahap ini proses hidrolisis, asidogenesis dan asetogenesis berjalan dengan baik jika pH asam, TAV meningkat, suhu kisaran $25-45{ }^{\circ} \mathrm{C}$ dan COD menurun. Pada tahap ini hubungan antara $\mathrm{pH}$ dan TAV berbanding terbalik. Semakin rendah pHnya maka semakin meningkat TAVnya. Jika dikaitkan dengan COD, hal ini disebabkan karena COD dari tanah gambut akan didegradasi oleh bakteri menjadi asam volatil sehingga COD turun, konsentrasi TAV meningkat kandungan asam volatil ini akan menurunkan pH. pada hari ke-24 dilakukan penambahan EM4 dan gula merah untuk meningkatkan TAV dan menambahkan nutrisi. pH ada tahap ini selama 32 hari adalah 4.57 yang mengindikasikan proses berjalan dengan baik. Pada tahap ini suhu berkisar $26-27{ }^{\circ} \mathrm{C}$, Menurut Tchobanoglous, 2004, temperatur pada rentang $15^{\circ} \mathrm{C}-45^{\circ} \mathrm{C}$ merupakan mikroorganisme Mesophilic, temperatur $25-35^{\circ} \mathrm{C}$ umumnya mampu mendukung laju reaksi biologi secara optimal dan menghasilkan pengolahan yang lebih stabil.

\subsubsection{Tahap Seeding pada Reaktor Metanogenesis}

Setiap hari dilakukan penggantian cairan manure sebanyak $10 \%$ dan dilakukan pengukuran $\mathrm{pH}$ dan suhu. Proses seeding pada reaktor metanogenesis dilakukan selama 20 hari. Berikut merupakan pengukuran pH dan suhu pada Gambar 3.1. 


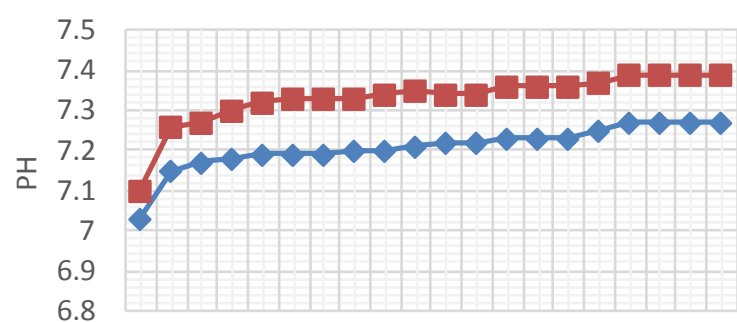

12345667891011121314151617181920 HARI KE-

$\sim$ Reaktor $1 \rightarrow$ Reaktor 2

(a)

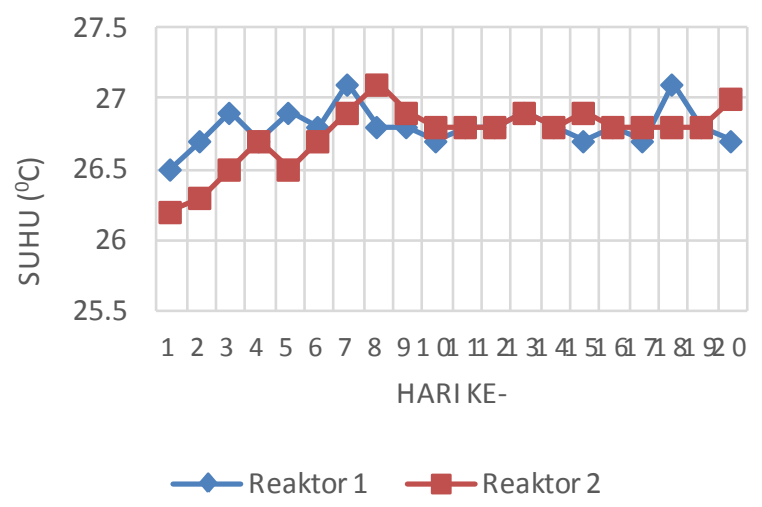

(b)

Gambar 3.1 (a) pengukuran pH Reaktor 1 dan 2 (b) Pengukuran Suhu Pada Reaktor 1 dan 2

Pada Gambar $\mathbf{3 . 1}$ menunjukan bahwa proses seeding berjalan dengan baik dilihat dari $\mathrm{pH}$ yang setiap harinya cenderung meningkat hal tersebut mengindikasikan bahwa bakteri tumbuh dan melekat pada media bambu (Grady dan Henry, 1990). Pada Gambar 3.1 (b), bahwa suhu pada saat proses seeding berfluktuasi selama 20 hari, menurut Tchobanoglous, 2004 , temperatur pada rentang $15^{\circ} \mathrm{C}-45^{\circ} \mathrm{C}$ merupakan mikroorganisme mesophilic, temperatur $25-35^{\circ} \mathrm{C}$ umumnya mampu mendukung laju reaksi biologi secara optimal dan menghasilkan pengolahan yang lebih stabil.

\subsubsection{Seeding Pada Media}

Pada tahapan ini bibit bakteri yang digunakan adalah bibit bakteri dari cairan Manure dalam kondisi anaerob. Setiap hari dilakukan penggantian cairan inokulum sebanyak $10 \%$ yaitu menambahkan dan mengeluarkan cairan sebanyak $146 \mathrm{ml}$ dan dilakukan pengukuran $\mathrm{pH}$ dan suhu. Berikut adalah Hasil penimbangan media selama 20 hari pada Tabel 3.4.

Tabel 3.4 Hasil Penimbangan berat Media

\begin{tabular}{|c|c|c|c|}
\hline No & $\begin{array}{c}\text { Sebelum } \\
\text { Dilakukan } \\
\text { Seeding } \\
\text { (gram) }\end{array}$ & $\begin{array}{c}\text { Setelah } \\
\text { Dilakukan } \\
\text { Seeding } \\
\text { (gram) }\end{array}$ & $\begin{array}{c}\text { Selisih Berat } \\
\text { Rata-rata } \\
\text { (gram) }\end{array}$ \\
\hline 1 & 0.2183 & 0.2586 & \multirow{12}{*}{$0.0856 /$ sumpit } \\
\hline 2 & 0.267 & 0.4332 & \\
\hline 3 & 0.179 & 0.3052 & \\
\hline 4 & 0.2557 & 0.3194 & \\
\hline 5 & 0.2298 & 0.2977 & \\
\hline 6 & 0.2771 & 0.3558 & \\
\hline 7 & 0.2972 & 0.3415 & \\
\hline 8 & 0.2211 & 0.3349 & \\
\hline 9 & 0.2527 & 0.3069 & \\
\hline 10 & 0.175 & 0.2913 & \\
\hline 11 & 0.2653 & 0.2796 & \\
\hline 12 & 0.3475 & 0.2749 & \\
\hline
\end{tabular}




\begin{tabular}{|c|c|c|c|}
\hline No & $\begin{array}{l}\text { Sebelum } \\
\text { Dilakukan } \\
\text { Seeding } \\
\text { (gram) }\end{array}$ & $\begin{array}{l}\text { Setelah } \\
\text { Dilakukan } \\
\text { Seeding } \\
\text { (gram) }\end{array}$ & $\begin{array}{c}\text { Selisih Berat } \\
\text { Rata-rata } \\
\text { (gram) }\end{array}$ \\
\hline 13 & 0.2751 & 0.3305 & \\
\hline 14 & 0.1637 & 0.2771 & \\
\hline 15 & 0.1371 & 0.347 & \\
\hline 16 & 0.2375 & 0.3217 & \\
\hline 17 & 0.157 & 0.281 & \\
\hline 18 & 0.2347 & 0.2965 & \\
\hline 19 & 0.1288 & 0.2805 & \\
\hline 20 & 0.1985 & 0.2964 & \\
\hline -rata & 0.2259 & 0.3115 & \\
\hline
\end{tabular}

Sumber : Hasil Pengukuran, 2017

Indikator tercapainya proses Seeding pada media bambu ini dapat diketahui dari penambahan berat media. Hal ini disebabkan pertumbuhan bakteri tidak dapat terlihat secara jelas karena media babu berwarna coklat kehitaman.

\subsubsection{Tahap Aklimatisasi}

Proses aklimatisasi bertujuan agar mikroorganisme yang digunakan dalam proses degradasi ini beradaptasi terlebih dahulu dengan limbah yang akan diolah, sehingga dapat bekerja secara maksimal (Rahayu, 2011). Berikut merupakan grafik dalam proses aklimatisasi pada Gambar 3.2

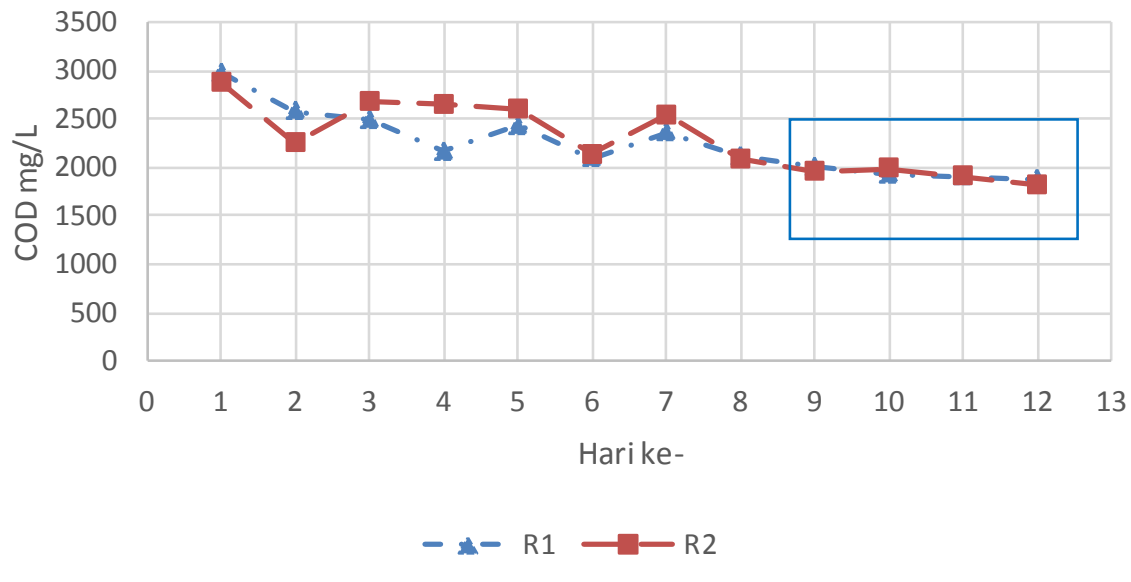

\section{Gambar 3.2 Pengukuran COD pada Tahap Aklimatisasi}

Aklimatisasi merupakan suatu proses adaptasi bakteri terhadap limbah yang akan diolah atau dalam penelitian ini terhadap substrat tanah gambut. Proses aklimatisasi ini dikatakan selesai ketika efisiensi penyisihan COD telah konstan dengan fluktuasi yang tidak lebih dari $10 \%$ (Herald, 2010). Selain itu sudah ada gas metan yang dihasilkan menandakan bahwa mikroba juga telah mulai bekerja (Indriyanti, 2003). Pada Gambar 3.2 menunjukkan bahwa sudah dalam kondisi stady dan efisiensi penyisihan COD konstan dan fluktuasi tidak lebih dari $10 \%$. Pada hari ke-9 sampai ke-12 tahap aklimatisasi sudah dalam kondisi stady. 


\subsubsection{Konsentrasi Gas Pada Proses Aklimatisasi}

Pada tahap aklimatisasi sudah ada gas metan yang terbentuk pada reaktor 1 dan reaktor 2 (reaktor metnogenesis). Berikut merupakan hasil pengukuran gas pada proses aklimatisasi dengan menggunakan orsat sederhana pada Tabel 3.5.

Tabel 3.5 Hasil pengukuran Gas Aklimatisasi

\begin{tabular}{cccc}
\hline \multirow{2}{*}{ Volume } & \multicolumn{2}{c}{ Reaktor } & \multirow{2}{*}{ Satuan } \\
\cline { 2 - 3 } & $\mathrm{R} 1$ (td 1 hari) & $\mathrm{R} 2$ (td 4 hari) & \\
\hline $\mathbf{\%} \mathbf{C O}_{\mathbf{2}}$ & 70 & 70 & $\%$ \\
\hline $\mathbf{\%} \mathbf{C H}_{\mathbf{4}}$ & 25 & 25 & $\%$ \\
\hline
\end{tabular}

Sumber : Hasil Pengukuran, 2017

Adanya gas pada proses aklimatisasi mengindikasikan bahwa ada aktitas mikroba dalam reaktor, konsentrasi $\mathrm{CH}_{4}$ pada Reaktor 1 adalah $25 \%$ dan pada Reaktor 2 adalah $25 \%$. Adanya gas metan yang dihasilkan menunjukkan bahwa mikroba juga telah mulai bekerja (Indriyanti, 2003).

\subsubsection{Running Waktu Detensi}

Pada penelitian ini variasi yang dilakukan adalah Variasi waktu detensi 1 hari dan 4 hari. Terdapat 2 unit reaktor metanogenesis dengan masing-masing memiliki waktu detensi yang berbeda. Berikut merupakan grafik antara $\mathrm{pH}$ dengan rasio TAV/alkalinitas dan suhu pada Gambar 3.3.

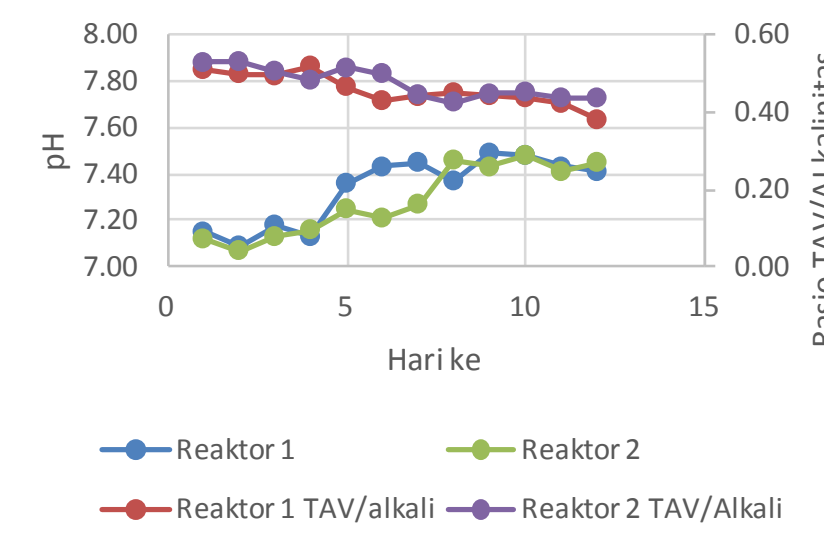

(a)

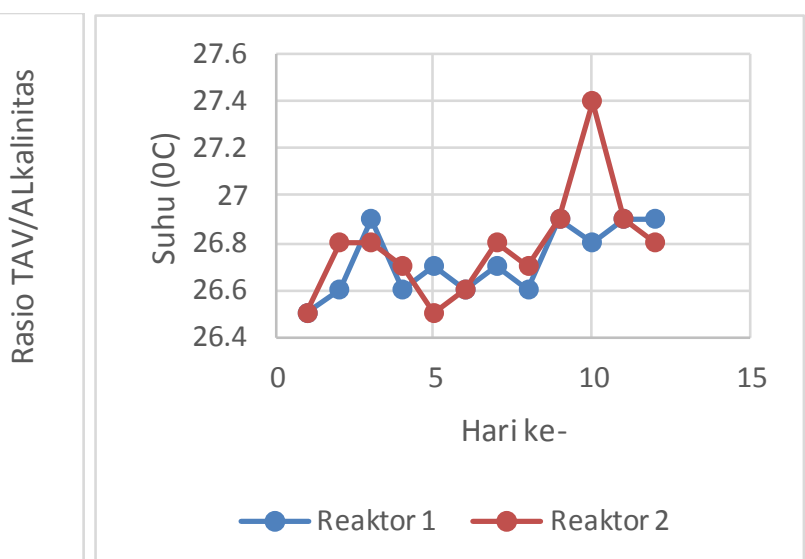

(b)

Gambar 3.3 (a) Hubungan pH dengan Rasio TAV/alkalinitas Reaktor 1 dan 2 (b) Suhu Pada reaktor 1 dan 2

Secara umum, mikroorganisme metanogen merupakan mikroorganisme yang sensitif terhadap pH dan mempunyai kisaran pH antara 6,6 dan 7,6 (Tchobanoglous, 2004). Nilai rasio TAV : alkalinitas yang dibawah 0,4 sangat baik bagi mikroorganisme metan untuk tumbuh sehingga produksi $\mathrm{CH}_{4}$ dapat berlangsung konstan (Grady dan Lim, 1990). Pada penelitian ini TAV/alkalinitas ada beberapa melebihi 0,4 tetapi masih pada rentang $\mathrm{pH}$ netral sehingga prosen metanogenesis masih berjalan dengan baik. Pada Gambar 3.3 (b) bahwa suhu pada saat running waktu detensi berfluktuasi Menurut Tchobanoglous, 2004, temperatur pada rentang $15^{\circ} \mathrm{C}-45^{\circ} \mathrm{C}$ merupakan mikroorganisme mesophilic, temperatur $25-35^{\circ} \mathrm{C}$ umumnya mampu mendukung laju reaksi biologi secara optimal dan menghasilkan pengolahan yang lebih stabil. 


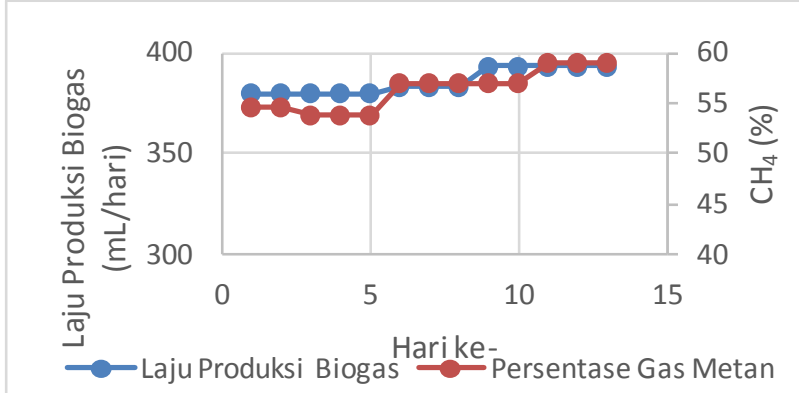

(a)

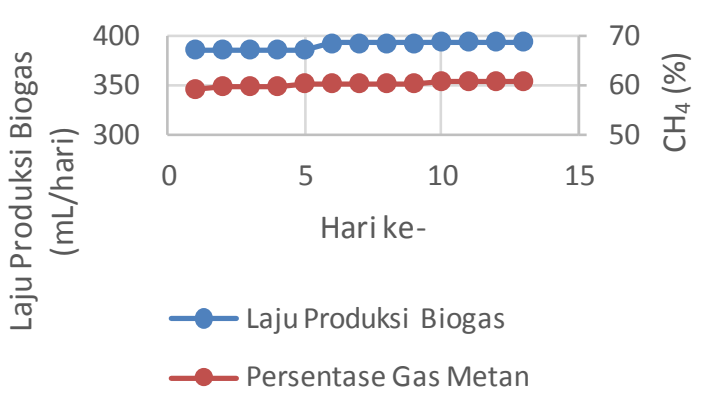

(b)

\section{Gambar 3.4 (a) Hubungan Laju Produksi Biogas dengan Konsentrasi $\mathrm{CH}_{4}$ Reaktor 1 (td 1 hari) (b) (a) Hubungan Laju Produksi Biogas dengan Konsentrasi $\mathrm{CH}_{4}$ Reaktor 2 (td 4 hari)}

Laju produksi biogas pada reaktor 1 dan 2 cenderung stabil begitu juga dengan dengan konsentrasi metan yang terbentuk. Dalam hal ini pada reaktor 1 dengan waktu detensi 1 hari dan reaktor 2 dengan waktu detensi 4 hari sudah dalam Kondisi Stady State. Hal ini diasumsikan bahwa laju produksi biogas dan metan setiap hari adalah sama rata, dengan tujuan untuk mengetahui gas yang terbentuk setiap harinya.

\section{KESIMPULAN}

Berat biofilm yang terbentuk setiap media sumpit adalah 0,0856 gram/sumpit. Laju produksi biogas terbesar pada waktu detensi 1 hari dan 4 hari masing-masing sebesar $393 \mathrm{ml} / \mathrm{hari}$ dan $395 \mathrm{ml} /$ hari sedangkan konsentrasi gas metan yang terbentuk adalah $59 \%$ dan $61 \%$. Variasi optimum dari dua variasi yang dilakukan adalah waktu detensi 4 hari dengan laju produktivitas biogas sebesar $395 \mathrm{ml} /$ hari dan konsentrasi gas metan sebesar $61 \%$.

\section{DAFTAR PUSTAKA}

Agus, F, dan I.G.M. Subiksa., 2008. Lahan Gambut : Potensi untuk Pertanian dan Aspek Lingkungan. Balai Penelitian Tanah, Bogor.

Andary, H. A., Oktiawan, W., \& Samudro, G. (2010). Studi Penurunan COD Dan Warna Pada Limbah Industri Tekstil Pt. Apac Inti Corpora dengan Kombinasi Anaerob-Aerob Menggunakan UASB dan HUASB. Universitas Diponegoro.

Anggra ini, D., Pertiwi, M. B., \& Bahrin, D. (2015). Pengaruh Jenis Sampah, Komposisi Masukan dan Waktu Tinggal terhadap Komposisi Biogas dari Sampah Organik. Jurnal Teknik Kimia, 18 (1).

Anonim. 2010a. Jenis-Jenis Tanah dan Proses Pembentukan Tanah. www.ardianrisqi.com/2010/01/jenis-jenis-tanah-dan-proses.html. Diakses pada 7 Desember 2016.

Bartlett, K.B. and R. Harris. 1993. Review And Assessment Of Methane Emissions From Wetlands. Chemosphere 26, pp. 261-320.

Fry, L.J., 1974, Practical Building of Methane Power Plant For Rural Energy Independence, 2nd edition, Chapel River Press, Hampshire-Great Britain.

Grady, \& Henry, L. C. (1990). Biological Wastewater Treatment. New York: Marcel Dekker. 
Grady P. Leslie, Jr., dan Lim C. Henry. 1990. Biological Wastewater Treatment. Marcel Dekker : New York.

Hanuputri, Adiya Dhiti. 2009. Kinetika Penyisihan Senyawa Organik Biowaste Fasa Cair dalam Upflow Fxied Bed Reakctor (UAF-B) Bermedia Bambu. Tesis Teknik Lingkungan Institu Teknologi Bandung, Bandung

Hayes, D. Thomas, Isaacson, H. Ronald, Frank, R. James. 1988. Production of High Methane Content Product by Two Phase Anaerobic Digestion. Gas Research Institute, US.

Herald, Denny. 2010. Pengaruh Rasio Waktu Reaksi Terhadap Waktu Stabilisasi Pada Penyisihan Senyawa Organik Dari Air Buangan Pabrik Minyak Kelapa Sawit Dengan Sequencing Batch Reactor Aerob. Jurusan Teknik Lingkungan, Fakultas Teknik, Universitas Andalas. Sumatera Barat.

Indriyanti. 2003. Proses Pembenihan (Seeding) dan Aklimatisasi pada Reaktor Tipe Fixed Bed. Penelitian Pusat Pengkajian dan Penerapan Teknologi Lingkungan, Badan Pengkajian dan Penerapan Teknologi, Jakarta.

Khairani, R. M., Ainun, S., \& Hartati, E. (2015). Pemanfaatan Sampah Organik Pasar Sebagai Bahan Baku Biodigester. Institut Teknologi Nasional Bandung, Bandung.

Price,E.C and Cheremisinoff,P.N.1981.Biogas Production and Utilization.Ann Arbor Science Publishers, Inc .United States of America

Rahayu, Nawangsari Seril. 2011. Kemampuan Upflow Anaerobic Fixed Bed (UAFB) Reaktor dalam Mempertahankan Kondisi Optimum dalam Penyisihan Senyawa Organik Pada Biowaste Fasa Cair Tanpa Menggunakan Pengaturan pH. Tesis Teknik Lingkungan Institut Teknologi Bandung, Bandung.

Saputro RR dan Putri DA. 2009. Pembuatan biogas dari limbah peternakan. http://eprints. undip.ac.id/3215/1/Pembuatan Biogas dari Limbah Peternakan.pdf.

(Diakses pada tanggal akses 8 Agustus 2017).

Sani. 2011. Pembuatan Karbon Aktif dari Tanah Gambut. Jurnal Teknik Kimia, 5 (2): 400-406

SNI 03-1965-1990 Tentang Cara Uji Kadar Air Tanah

SNI 06-2422-1991 Tentang Cara Uji Alkalinitas

SNI 6989.72:2009 Tentang Cara Uji Kebutuhan Oksigen Biokimia (Biochemical Oxygen DemandBOD)

SNI 06-6989.14-2004 Tentang Cara Uji Oksigen Terlarut Secara Yodometri (Modifikasi Azida)

SNI 06-6989.11-2004 Tentang Cara uji pH dan Temperatur

SNI-0029:2008 Tentang Pengukuran Orsat Analizer

SMWW 5220 C. "Chemical Oxygen Demand'. American Public Health Associate, American Water Work Association, Water Environment Federal, 2015

SMWW 5570 C. "Total Volatile Acid". American Public Health Associate, American Water Work Association, Water Environment Federal, 2015

Tchobanoglous, G., H.Theissen,S.A Vigil. 2004. Integrated Solid Waste Management, McGraw Hill.USA

Wahyudi, Djoko, Wardana, ING dan Hamidi, Nurkholis. 2012. Pengaruh Kadar Karbondioksida $\left(\mathrm{CO}_{2}\right)$ dan Nitrogen $\left(\mathrm{N}_{2}\right)$ Pada Karakteristik Pembakaran Gas Metana. Jurusan Teknik Mesin, Program Magister dan Doktor FT UB, Fakultas Teknik, Universitas Panca Marga, Probolinggo.

Wetland

International. 2009.

Gambut.

http://indonesia. wetlands.org/Kegiatankami/Gambut/tabid/2838/language/id-

ID/Default.aspx. (Diakses pada tanggal 20 Juli 2016). 